\title{
PENGARUH KADAR PEREKAT TERHADAP SIFAT PAPAN PARTIKEL BAMBU
}

\section{(Effect of Resin Portion on Bamboo Particleboard Properties)}

\author{
Oleh/By : \\ I.M. Sulastiningsih ${ }^{1)}$, Novitasari ${ }^{2)}$ \& Agus Turoso ${ }^{3)}$
}

\begin{abstract}
The objective of the study was to determine the effects of resin portion on bamboo particleboardproperties. Strandlike bamboo particles of Dendrocalamus asper were used as raw material for the manufacture of bamboo particleboards using urea formaldebyde resin. Laboratory scale bamboo particleboards at various resin portions (8; 9, 10, 11 and 12\% of dry weight bamboo particles) were manufactured with targeted density of $0.70 \mathrm{~g} / \mathrm{cm}^{3}$.

Results indicated that physical and mechanical properties of bamboo particleboard were significantly affected by the resin portion. The higher resin portion gave better physical and mechanical properties of bamboo particleboards. Resin portion of $11 \%$ was the minimum level in manufacturing bamboo particleboard with adequate strength and dimensional stability, to meet the Indonesian Standard requirements.
\end{abstract}

Keywords: Bamboo, particleboard, resin portion, physical and mechanical properties

\begin{abstract}
ABSTRAK
Penelitian ini bertujuan untuk mengetahui pengaruh kadar perekat terhadap sifat papan partikel bambu. Bambu yang digunakan adalah bambu betung (Dendrocalamus asper), sedangkan perekatnya adalah urea formaldehida (UF) cair. Bentuk partikel bambu yang digunakan adalah untai. Papan partikel bambu sekala laboratorium dibuat dengan target kerapatan $0,70 \mathrm{~g} / \mathrm{cm}^{3}$ dengan kadar perekat bervariasi yaitu $8,9,10,11$ dan $12 \%$ dari berat kering partikel bambu.

Hasil penelitian menunjukkan bahwa sifat fisis dan mekanis papan partikel bambu sangat dipengaruhi oleh kadar perekat yang digunakan. Semakin tinggi kadar perekat semakin baik sifat papan partikel bambu yang dihasilkan. Penggunaan kadar perekat minimum 11\% dari berat kering partikel bambu menghasilkan papan partikel bambu yang cukup kuat dan stabil serta memenuhi persyaratan Standar Nasional Indonesia.
\end{abstract}

Kata kunci: Bambu, papan partikel, kadar perekat, sifat fisis dan mekanis

\footnotetext{
1) Peneliti pada Pusat Penelitian dan Pengembangan Hasil Hutan, Bogor

2) Alumni Fakultas Pertanian Universitas Lampung

3) Teknisi pada Pusat Penelitian dan Pengembangan Hasil Hutan, Bogor
} 


\section{PENDAHULUAN}

Masalah serius yang dihadapi oleh industri pengolahan kayu di Indonesia saat ini adalah kekurangan bahan baku kayu. Hal ini terjadi karena kecepatan pemanfaatan kayu tidak seimbang dengan kecepatan pembangunan tegakan baru. Sementara itu kebutuhan kayu untuk mebel, bahan bangunan dan keperluan lain terus meningkat seiring dengan pertambahan penduduk serta sebagai pengganti kayu yang rusak, lapuk atau dimakan rayap. Oleh karena itu perlu dicari bahan baku alternatif untuk industri pengolahan kayu. Bambu merupakan salah satu bahan yang dapat digunakan untuk tujuan tersebut. Pemanfaatan bambu untuk papan partikel dapat mengurangi permintaan kayu untuk industri papan partikel.

Bambu merupakan salah satu hasil hutan bukan kayu yang dapat digunakan untuk berbagai keperluan, oleh karena itu bambu termasuk tanaman serbaguna. Tanaman bambu telah digunakan masyarakat sejak jaman dahulu antara lain untuk bahan bangunan, mebel, alat rumah tangga dan barang kerajinan. Di Indonesia bambu dapat dijumpai baik di daerah pedesaan maupun di dalam kawasan hutan. Semua jenis tanah dapat ditanami bambu kecuali tanah di daerah pantai. Pada tanah ini kalaupun terdapat bambu, pertumbuhannya lambat dan batangnya kecil. Tanaman bambu dapat dijumpai mulai dari dataran rendah sampai dataran tinggi, dari pegunungan berbukit dengan lereng curam sampai landai (Sastrapraja, et al., 1977).

Menurut Widjaja (2001) bambu di Indonesia terdiri atas 143 jenis. Di Jawa diperkirakan hanya ada 60 jenis bambu. Di antara jenis-jenis yang ada di Jawa, 16 jenis tumbuh juga di pulau-pulau lainnya, 26 jenis merupakan jenis introduksi, dan 14 jenis di antaranya hanya tumbuh di Kebun Raya Bogor dan Cibodas. Pada tahun 2000 diperkirakan luas tanaman bambu di Indonesia adalah sebesar 2.104.000 ha yang terdiri dari 690.000 ha luas tanaman bambu di dalam kawasan hutan dan 1.414 .000 ha luas tanaman bambu di luar kawasan hutan (Anonim, 2005).

Industri pengolahan bambu di Indonesia, yang telah berkembang dan telah diekspor produknya adalah supit, mebel dan barang kerajinan. Dari proses pengolahan bambu tersebut maka diperoleh limbah berupa potongan bambu khususnya bagian pangkal dengan panjang ruas yang tidak beraturan yang jumlahnya cukup banyak. Untuk meningkatkan efisiensi pemanfaatan bambu maka limbah berupa potongan bambu tersebut masih dapat dimanfaatkan sebagai bahan baku papan partikel. Sebagaimana diketahui bahwa salah satu keuntungan pembuatan papan partikel adalah dapat memanfaatkan berbagai macam bahan berlignoselulosa dengan ukuran yang kecil sedangkan produk yang dihasilkan dapat diperoleh dalam ukuran yang besar. Dalam tulisan ini disajikan hasil penelitian pengaruh kadar perekat terhadap sifat papan partikel bambu.

\section{BAHAN DAN METODE}

\section{A. Bahan}

Bambu yang digunakan dalam penelitian ini adalah bambu betung (Dendrocalamus asper) berumur sekitar 4 tahun berasal dari Bogor, Jawa Barat. Perekat yang digunakan adalah urea formaldehida (UA 145) cair diperoleh dari PT PAI Probolinggo dan pengerasnya $\mathrm{NH}_{4} \mathrm{Cl}$. 


\section{B. Metode}

\section{Pembuatan partikel bambu}

Bambu dipotong-potong sepanjang $40 \mathrm{~cm}$ kemudian dibelah menjadi dua bagian. Masing-masing belahan bambu dibuat beberapa takik sepanjang $5 \mathrm{~cm}$ pada kedua sisi panjangnya kemudian diserut dengan menggunakan mesin pembuat wol kayu sehingga diperoleh partikel bambu berupa untai (strand) dengan ukuran panjang $5 \mathrm{~cm}$, lebar $4 \mathrm{~mm}$ dan tebal 0,4 mm. Partikel bambu tersebut kemudian dikeringkan dalam oven hingga kadar airnya mencapai $4 \%$.

\section{Pembuatan papan partikel bambu}

Ukuran papan partikel yang dibuat adalah $30 \times 30 \times 1 \mathrm{~cm}$. Perekat yang digunakan adalah urea formaldehida (UF) cair. Banyaknya perekat yang digunakan dalam pembuatan papan partikel bambu bervariasi yaitu 8, 9, 10, 11 dan 12\% dari berat kering partikel bambu. Kedalam perekat urea formaldehida cair ditambahkan pengeras $\left(\mathrm{NH}_{4} \mathrm{Cl}\right)$ sebanyak $1 \%$ dari berat perekat. Target kerapan papan partikel bambu yang dibuat adalah $0,70 \mathrm{~g} / \mathrm{cm}^{3}$. Papan partikel bambu dibuat pada suhu $140^{\circ} \mathrm{C}$ dengan tekanan spesifik $25 \mathrm{~kg} / \mathrm{cm}^{2}$ selama 10 menit. Untuk masing-masing perlakuan (kadar perekat) dibuat 3 buah papan. Setelah pengempaan selesai papan partikel bambu yang dihasilkan diangin-anginkan selama 7 hari sebelum diuji sifatnya.

\section{Pengujian sifat fisis dan mekanis papan partikel}

Pembuatan contoh uji untuk pengujian sifat fisis dan mekanis papan partikel bambu tersebut dilakukan 7 hari setelah papan partikel bambu selesai dibuat. Sifat papan partikel yang diuji meliputi kadar air, kerapatan, pengembangan tebal, keteguhan rekat internal, modulus patah dan modulus elastisitas. Prosedur pengujian menurut Standar Nasional Indonesia (1996).

\section{Analisis Data}

Untuk mengetahui pengaruh kadar perekat terhadap sifat fisis dan mekanis papan partikel bambu maka dilakukan sidik ragam dengan rancangan percobaan acak lengkap. Sebagai perlakuan adalah kadar perekat yang terdiri dari 5 tingkat $(8,9,10,11$ dan 12\%). Banyaknya ulangan adalah 3 buah. Nilai rata-rata sifat fisis dan mekanis papan partikel bambu dibandingkan dengan Standar Nasional Indonesia (1996) mengenai mutu papan partikel.

\section{HASIL DAN PEMBAHASAN}

Hasil pengujian sifat fisis dan mekanis papan partikel bambu disajikan dalam Tabel 1. Untuk mengetahui pengaruh kadar perekat terhadap sifat papan partikel bambu dilakukan analisis keragaman dan hasilnya disajikan pada Tabel 2 , sedangkan uji bedanya tercantum pada Tabel3. 
Tabel 1. Nilai rata-rata sifat fisis dan mekanis papan partikel bambu Table 1. Mean values of physical and mechanical properties of bamboo particleboard

\begin{tabular}{|c|c|c|c|c|c|c|}
\hline \multirow{2}{*}{ No } & \multirow{2}{*}{$\begin{array}{l}\text { Sifat papan partikel bambu } \\
\text { (Bamboo particleboard properties) }\end{array}$} & \multicolumn{5}{|c|}{ Kadar perekat (Resin portion) } \\
\hline & & $8 \%$ & $9 \%$ & $10 \%$ & $11 \%$ & $12 \%$ \\
\hline 1 & $\begin{array}{l}\text { Kadar air } \\
\text { (Moisture content ), \% }\end{array}$ & 7,12 & 7,20 & 7,12 & 7,25 & 7,02 \\
\hline 2 & $\begin{array}{l}\text { Kerapatan } \\
\text { (Density), } \mathrm{g} / \mathrm{cm}^{3}\end{array}$ & 0,68 & 0,70 & 0,70 & 0,70 & 0,71 \\
\hline 3 & $\begin{array}{l}\text { Pengembangan tebal } \\
\text { (Thickness swelling), } \%\end{array}$ & 14,01 & 12,42 & 11,54 & 10,62 & 8,89 \\
\hline 4 & $\begin{array}{l}\text { Penyerapan air } \\
\text { (Water absorption), \% }\end{array}$ & 69,63 & 59,49 & 59,08 & 50,87 & 48,68 \\
\hline 5 & $\begin{array}{l}\text { Keteguhan rekat internal } \\
\text { (Internal bond strength), } \mathrm{kg} / \mathrm{cm}^{2}\end{array}$ & 1,58 & 1,92 & 2,86 & 3,19 & 3,71 \\
\hline 6 & $\begin{array}{l}\text { Modulus patah } \\
\text { (Modulus of rupture), } \mathrm{kg} / \mathrm{cm}^{2}\end{array}$ & 56,86 & 114,17 & 117,28 & 136,75 & 187,56 \\
\hline 7 & $\begin{array}{l}\text { Modulus elastisitas } \\
\text { (Modulus of elasticity), } \mathrm{kg} / \mathrm{cm}^{2}\end{array}$ & 7.485 & 12.676 & 14.525 & 20.134 & 25.315 \\
\hline
\end{tabular}

Kerapatan papan partikel bambu yang dibuat berkisar antara $0,68 \mathrm{~g} / \mathrm{cm}^{3}$ hingga 0,71 $\mathrm{g} / \mathrm{cm}^{3}$ dengan rata-rata $0.70 \mathrm{~g} / \mathrm{cm}^{3}$. Dengan demikian papan partikel tersebut memenuhi persyaratan Standar Indonesia atau SNI (1996) karena nilainya ada di antara 0,50 - 0,70 g/ $\mathrm{cm}^{3}$ dan memenuhi Standar Jepang atau JIS (Anonim, 2003) karena nilainya ada di antara 0,40 $0,90 \mathrm{~g} / \mathrm{cm}^{3}$ serta memenuhi Standar FAO (Anonim 1966) karena nilainya ada di antara 0,40 $0,80 \mathrm{~g} / \mathrm{cm}^{3}$.

Kadar air papan partikel bambu yang dibuat berkisar antara 7,02 - 7,25\% dengan ratarata $7,14 \%$. Dengan demikian kadar air papan partikel bambu yang dibuat dengan berbagai kadar perekat memenuhi Standar Indonesia, Standar Jepang dan Standar FAO karena nilainya kurang dari $12 \%$.

Tabel 2. Nilai $F$ hitung pengaruh kadar perekat terhadap sifat papan partikel bambu Table 2. Calculated $F$ values of the effect of resin portion on bamboo particleboard properties

\begin{tabular}{|c|l|c|}
\hline No & $\begin{array}{l}\text { Sifat papan partikel bambu } \\
(\text { Bamboo particleboard properties) }\end{array}$ & $\begin{array}{c}\mathrm{F}_{\text {hitung }} \\
\left(\mathrm{F}_{\text {calculated }}\right)\end{array}$ \\
\hline 1 & Pengembangan tebal (Thickness swelling), \% & $24,41^{* *}$ \\
2 & Penyerapan air (Water absorption), \% & $17,31^{* *}$ \\
3 & Keteguhan rekat internal (Internal bond strength), $\mathrm{kg} / \mathrm{cm}^{2}$ & $109,62^{* *}$ \\
4 & Modulus patah (Modulus of rupture), $\mathrm{kg} / \mathrm{cm}^{2}$ & $16,77^{* *}$ \\
5 & Modulus elastisitas (Modulus of elasticity), $\mathrm{kg} / \mathrm{cm}^{2}$ & $8,78^{* *}$ \\
\hline
\end{tabular}

Keterangan (Remark) $* *$ = Sangat nyata (Highly significant) 
Nilai pengembangan tebal papan partikel bambu setelah direndam dalam air dingin selama 24 jam berkisar antara 8,89 - 14,01\% dengan nilai rata-rata 11,50\% (Tabel 1). Dengan demikian papan partikel bambu yang memenuhi syarat Standar Indonesia, Standar Jepang dan Standar FAO adalah papan partikel bambu yang dibuat dengan kadar perekat 10, 11 dan $12 \%$ karena nilai pengembangan tebalnya lebih kecil dari $12 \%$. Hasil sidik ragam pada Tabel 2 menunjukkan bahwa kadar perekat sangat berpengaruh terhadap pengembangan tebal papan partikel bambu. Semakin tinggi kadar perekat semakin kecil pengembangan tebal papan partikel bambu. Hasil penelitian ini sejalan dengan pendapat Maloney (1977) dan hasil penelitian terdahulu mengenai papan partikel dengan bahan baku kayu (Sulastiningsih, Memed dan Sutigno, 1988, Razali dan Sulastiningsih, 1991, serta Memed, Sulastiningsih dan Sutigno, 1992). Jumlah perekat yang banyak akan meningkatkan ikatan antar partikel sehingga papan partikel bambu yang dihasilkan lebih tahan terhadap air dan lebih stabil.

Nilai penyerapan air papan partikel bambu setelah direndam dalam air dingin selama 24 jam berkisar antara 48,68 - 69,63\% dengan rata-rata 57,55\%. Menurut Standar FAO nilai penyerapan air untuk papan partikel berkerapatan sedang adalah $20-75 \%$, dengan demikian semua papan partikel bambu yang dibuat dengan berbagai kadar perekat memenuhi standar tersebut. Pada Standar Indonesia dan Standar Jepang besarnya penyerapan air papan partikel tidak dipersyaratkan. Hasil sidik ragam pada Tabel 2 menunjukkan bahwa kadar perekat sangat berpengaruh terhadap sifat penyerapan air papan partikel bambu. Semakin tinggi kadar perekat semakin kecil penyerapan air papan partikel bambu. Hal ini sejalan dengan hasil penelitian terdahulu (Sulastiningsih et al., 1988, Razali dan Sulastiningsih, 1991, dan Memed et al., 1992).

Keteguhan rekat internal papan partikel bambu berkisar antara 1,5-3,71 kg/ $\mathrm{cm}^{2}$ dengan rata-rata $2,65 \mathrm{~kg} / \mathrm{cm}^{2}$. Dengan demikian papan partikel bambu yang dibuat semuanya memenuhi Standar Indonesia dan Standar Jepang karena nilainya lebih dari $1,5 \mathrm{~kg} / \mathrm{cm}^{2}$. Sedangkan jika dibandingkan dengan Standar FAO maka papan partikel bambu yang memenuhi syarat keteguhan rekat internalnya adalah papan partikel yang dibuat dengan kadar perekat minimum 10\% karena nilainya lebih dari $2 \mathrm{~kg} / \mathrm{cm}^{2}$. Hasil sidik ragam pada Tabel 2 menunjukkan bahwa kadar perekat sangat berpengaruh terhadap keteguhan rekat internal papan partikel bambu. Semakin tinggi kadar perekat semakin tinggi pula nilai keteguhan rekat internal papan partikel bambu. Hal ini dikarenakan semakin banyak perekat, semakin baik ikatan antar partikel yang terjadi pada papan partikel bambu yang dihasilkan.

Nilai modulus patah papan partikel bambu berkisar antara $56,86-187,56 \mathrm{~kg} / \mathrm{cm}^{2}$ dengan rata-rata $122,52 \mathrm{~kg} / \mathrm{cm}^{2}$. Dengan demikian papan partikel bambu yang memenuhi syarat menurut Standar Indonesia, Standar Jepang dan Standar FAO adalah papan partikel yang dibuat dengan kadar perekat minimum $9 \%$ karena nilai modulus patahnya berturutturut lebih dari 80, $82 \mathrm{dan} 100 \mathrm{~kg} / \mathrm{cm}^{2}$. Hasil sidik ragam pada Tabel 2 menunjukkan bahwa kadar perekat sangat berpengaruh terhadap modulus patah papan partikel bambu. Semakin tinggi kadar perekat semakin tinggi pula modulus patah papan partikel bambu.

Nilai modulus elastisitas papan partikel bambu berkisar antara $7.485-25.315 \mathrm{~kg} / \mathrm{cm}^{2}$ dengan rata-rata $16.027 \mathrm{~kg} / \mathrm{cm}^{2}$. Dengan demikian papan partikel bambu yang memenuhi syarat menurut Standar Indonesia, Standar FAO dan Standar Jepang adalah papan partikel yang dibuat dengan kadar perekat minimum 11\% karena nilai modulus elastisitasnya berturut-turut lebih dari 15.000 dan $20.000 \mathrm{~kg} / \mathrm{cm}^{2}$. Hasil sidik ragam pada Tabel 2 
menunjukkan bahwa kadar perekat sangat berpengaruh terhadap modulus elastisitas papan partikel bambu. Semakin tinggi kadar perekat semakin tinggi pula modulus elastisitas papan partikel bambu.

Tabel 3. Uji beda pengaruh kadar perekat terhadap sifat papan partikel bambu Table 3. Test of significant difference of resin portion effect on bamboo particleboard properties

\begin{tabular}{|c|c|c|c|c|c|c|}
\hline No & $\begin{array}{l}\text { Sifat papan partikel bambu } \\
\text { (Bamboo particleboard properties) }\end{array}$ & \multicolumn{5}{|c|}{$\begin{array}{l}\text { Perbandingan nilai rata-rata } \\
\text { (Mean value comparison) }\end{array}$} \\
\hline 1 & $\begin{array}{l}\text { Pengembangan tebal (Thickness } \\
\text { swelling), } \% \\
\text { D } 0,01=2,38\end{array}$ & $\begin{array}{c}\mathrm{P}_{5} \\
8,89\end{array}$ & $\begin{array}{c}\mathrm{P}_{4} \\
10,62\end{array}$ & $\begin{array}{c}\mathrm{P}_{3} \\
11,54\end{array}$ & $\begin{array}{c}\mathrm{P}_{2} \\
12,42\end{array}$ & $\begin{array}{l}P_{1} \\
14,01\end{array}$ \\
\hline 2 & $\begin{array}{l}\text { Penyerapan air (Water } \\
\text { absorption), } \% \\
\text { D } 0,01=12,24\end{array}$ & $\begin{array}{c}\mathrm{P}_{5} \\
48,68\end{array}$ & $\begin{array}{c}\mathrm{P}_{4} \\
50,87\end{array}$ & $\begin{array}{c}\mathrm{P}_{3} \\
59,08\end{array}$ & $\begin{array}{c}\mathrm{P}_{2} \\
59,49\end{array}$ & $\begin{array}{l}P_{1} \\
69,63\end{array}$ \\
\hline 3 & $\begin{array}{l}\text { Keteguhan rekat internal (Internal } \\
\text { bond strength), } \mathrm{kg} / \mathrm{cm}^{2} \\
\mathrm{D} 0,01=0,52\end{array}$ & $\begin{array}{c}\mathrm{P}_{1} \\
1,58\end{array}$ & $\begin{array}{c}\mathrm{P}_{2} \\
1,92\end{array}$ & $\begin{array}{c}\mathrm{P}_{3} \\
2,86\end{array}$ & $\begin{array}{l}\mathrm{P}_{4} \\
3,19\end{array}$ & $\begin{array}{l}P_{5} \\
3,71\end{array}$ \\
\hline 4 & $\begin{array}{l}\text { Modulus patah (Modulus of } \\
\text { rupture), } \mathrm{kg} / \mathrm{cm}^{2} \\
\text { D } 0,01=70,48\end{array}$ & $\begin{array}{c}P_{1} \\
56,86\end{array}$ & $\begin{array}{c}\mathrm{P}_{2} \\
114,17\end{array}$ & $\begin{array}{c}\mathrm{P}_{3} \\
117,28\end{array}$ & $\begin{array}{c}\mathrm{P}_{4} \\
136,75\end{array}$ & $\begin{array}{c}P_{5} \\
187,56\end{array}$ \\
\hline 5 & $\begin{array}{l}\text { Modulus elastisitas (Modulus of } \\
\text { elasticity), } \mathrm{kg} / \mathrm{cm}^{2} \\
\text { D } 0,01=1.424\end{array}$ & $\begin{array}{c}P_{1} \\
7.485\end{array}$ & $\begin{array}{c}P_{2} \\
12.676\end{array}$ & $\begin{array}{c}P_{3} \\
14.525\end{array}$ & $\begin{array}{c}\mathrm{P}_{4} \\
20.134\end{array}$ & $\begin{array}{c}\mathrm{P}_{5} \\
25.315\end{array}$ \\
\hline
\end{tabular}

Keterangan (Remarks) : P $=$ Kadar perekat (Resin portion); $\mathrm{P} 1=8 \% ; \mathrm{P} 2=9 \% ; \mathrm{P} 3=10 \% ; \mathrm{P} 4=11 \%$; $\mathrm{P} 5=12 \% ; \mathrm{D}=$ Nilai beda (Difference value); __ $=$ Tidak berbeda nyata $($ Not significant difference) 
Secara keseluruhan dapat diketahui bahwa dengan meningkatnya kadar perekat dalam pembuatan papan partikel bambu, terjadi peningkatan nilai keteguhan rekat internal, modulus patah dan modulus elastisitas. Sebaliknya nilai pengembangan tebal dan penyerapan air papan partikel bambu menurun dengan meningkatnya kadar perekat, yang berarti papan partikel bambu yang dihasilkan lebih stabil. Dengan demikian semakin tinggi kadar perekat yang digunakan dalam pembuatan papan partikel bambu semakin baik sifat papan partikel bambu yang dihasilkan.

\section{KESIMPULAN}

1. Papan partikel bambu yang dibuat termasuk papan partikel berkerapatan sedang.

2. Sifat fisis dan mekanis papan partikel bambu sangat dipengaruhi oleh kadar perekat yang digunakan. Semakin tinggi kadar perekat semakin baik sifat papan partikel bambu yang dihasilkan.

3. Penggunaan kadar perekat minimum 11\% sudah menghasilkan papan partikel bambu yang memenuhi persyaratan menurut Standar Indonesia, Standar Jepang dan Standar FAO.

\section{DAFTAR PUSTAKA}

Anonim. 1966. Plywood and Other Wood-based Panels. Food and Agricultural Organization of United Nation. Rome.

1996. Mutu Papan Partikel. Dewan Standardisasi Nasional-DSN. Jakarta. SNI 032105-1996

2003. Particleboards. Japanese Standards Association. Tokyo. Japanese Industrial Standard. JIS A 5908: 2003.

2005. Global Forest Resources Assessment Update 2005. Indonesia. Country Report on Bamboo Resources. Forest Resources Assessment Working Paper (Bamboo). Food and Agriculture Organization of the United Nations, Forestry Department and International Network for Bamboo and Rattan (INBAR), Jakarta, May, 2005.

Maloney, T.M. 1977. Modern Particleboard and Dry-Process Fiberboard Manufacturing. Miller Freeman Publication. San Francisco.

Memed, R. , I.M. Sulastiningsih dan P. Sutigno. 1992. Pengaruh senyawa boron terhadap beberapa sifat papan partikel karet. Jurnal Penelitian Hasil Hutan 10(5) :160-166. Pusat Penelitian dan Pengembangan Hasil Hutan. Bogor.

Razali, A.K. and I.M. Sulastiningsih. 1991. Effects of varying resin content and compression ratio on properties of isocyanate-bonded particleboard. Manuscript for the Seminar on Evaluation of Achievements in IRPA Research in The Fifth Malaysian Plan-Industrial Sector, 21-24 December 1991. Universiti Utara Malaysia. Sintok. Kedah. 
JURNAL Penelitian Hasil Hutan Vol. 24 No. 1, Februari 2006: 1-8

Sastrapraja, S., E.A. Widjaja, S. Prawiroatmodjo dan S. Soenarko. 1977. Beberapa Jenis Bambu. Lembaga Biologi Nasional. Lembaga Ilmu Pengetahuan Indonesia. Bogor.

Sulastiningsih, I.M., R. Memed dan P. Sutigno. 1988. Pengaruh kadar perekat dan campuran kulit terhadap sifat fisis dan mekanis papan partikel tusam. Jurnal Penelitian Hasil Hutan 5(4) :184-191. Pusat Penelitian dan Pengembangan Hasil Hutan. Bogor.

Widjaya, E.A. 2001. Identikit Jenis-jenis Bambu di Jawa. Pusat Penelitian dan Pengembangan Biologi, LIPI. Balai Penelitian Botani, Herbarium Bogoriense, Bogor. Indonesia. 